\title{
Synthesis, Characterization, and Application of Co-Al-Zn Layered Double Hydroxide/Hydrochar Composite for Simultaneous Removal of Cationic and Anionic Dyes
}

\author{
Najma Memon, ${ }^{1}$ Urooj Kanwal, ${ }^{1}$ Abdullah Memon, ${ }^{2}$ Safia Sanam Memon, \\ and Saima Qayoom Memon $\mathbb{1}^{3}$ \\ ${ }^{1}$ National Centre of Excellence in Analytical Chemistry, University of Sindh, Jamshoro, Pakistan \\ ${ }^{2}$ National Institute of Oceanography, Karachi, Pakistan \\ ${ }^{3}$ M.A. Kazi Institute of Chemistry, University of Sindh, Jamshoro, Pakistan
}

Correspondence should be addressed to Saima Qayoom Memon; msaima77@gmail.com

Received 4 July 2021; Revised 1 October 2021; Accepted 19 October 2021; Published 2 December 2021

Academic Editor: Doina Humelnicu

Copyright ( $\odot 2021$ Najma Memon et al. This is an open access article distributed under the Creative Commons Attribution License, which permits unrestricted use, distribution, and reproduction in any medium, provided the original work is properly cited.

Decontamination of organic dyes from wastewater requires efficient and compatible materials that must be able to remove dyes with different charges at the same time. In this study, composites of layered double hydroxide (LDH) and hydrochar (HC) were prepared and tested for use as general-purpose sorbents for the simultaneous removal of cationic and anionic dyes (i.e., methylene blue (MB), methyl orange (MO), and reactive yellow (RY)). Characterization studies reveal that the surface functional groups on composites are $-\mathrm{OH}, \mathrm{NO}_{3}, \mathrm{M}-\mathrm{O}$ bonds. It was observed that crystallinity of $\mathrm{LDH}$ decreased with an increasing amount of $\mathrm{HC}$. Preliminary experiments showed that the dyes (i.e., MB, MO, and RY) were well removed simultaneously onto the composite with HC $(2.0 \mathrm{~g} \mathrm{HC} /$ prepared composite). This composite was selected for more experiments, and the adsorption efficiency was optimized by the multivariate technique using the response surface methodology (RSM). Removal efficiency of $100 \%$ was obtained for all three dyes with an adsorption capacity of $243,5.3$, and $16.3 \mu \mathrm{mol} \mathrm{g}^{-1}$ for MB, MO, and RY, respectively. Elovich's initial intake rates $(\alpha)$ were $4,272,441$, and $99.5 \mathrm{mg} \mathrm{g}^{-1} \mathrm{~min}^{-1}$ for $\mathrm{RY}, \mathrm{MB}$, and MO, respectively. Data fitted in various models suggested second-order multiplex kinetics, where the surface heterogeneity response was sorbate dependent.

\section{Introduction}

Due to the fast growth of urbanization and industrialization, the issue of water contamination has been worsening [1]. Many industries such as textile, tanning, printing and cosmetic, paper, and pulp are accountable for contamination of water reservoirs with various organic and inorganic pollutants [2]. Among them, dyes, polynuclear aromatics, phenolics, antibiotics, and pesticides are considered as organic persistent pollutants [3]. The textile industry is the topmost user of dyes [4]. Furthermore, due to improper dyeing process, approximately $10-15 \%$ of the dyes pass in the effluents of textile units and impart highly dense color to industrial wastewater [5]. This not only threatens the ecological life but also obstructs light penetration that can affect the photochemical activity of the aquatic environment [6]. Therefore, it is necessary to treat industrial effluent effectively before draining it into the environment. Conventionally, dyes removal has been performed by biological, chemical, and physical methods [7]. On a large scale, many dyes are imperfectly biodegradable or unmanageable to environmental conditions due to their complex large molecular structure, which leads to unidentified degradation products [6]. Physical removal technologies such as adsorption are however feasible as the whole molecule is taken up from an aqueous solution onto an adsorbate that can be desorbed or treated in a detached environment leaving the water stream free from any degradation product. For the removal of dyes from wastewater, many adsorbent materials have been developed, including coal fly ash [8], bentonite, 
sagaun sawdust, leaf-based materials [9], surfactant-modified natural zeolite, tin sulfide nanoparticle loaded on activated carbon, $\mathrm{Mg}-\mathrm{Fe}$-based hydrotalcites, modified chitin, and so on [10]. Recently, cross-linked chitosan-based hydrogels are critically reviewed as adsorbents for the removal of textile dyes. These hydrogels have many advantages but are not effective for cationic dyes and are chemically unstable or can have a $\mathrm{pH}$-sensitive behavior [11]. Cheaper, green, and scalable materials that can effectively remove diverse dyes (cationic/anionic) must be developed. This study reports the synthesis of a composite of layered double hydroxides (LDH) and carbonaceous material obtained under hydrothermal condition (HC). LDH possesses excessive anion exchange capacity and high layer charge densities. Both characteristics support strong interaction with anion pollutants. However, HC is similar to activated carbon but possesses more negative charges, therefore capable of interacting with cationic molecules [12].

LDHs or hydrotalcite-like compounds are a huge family of two-dimensional (2D) anionic clay materials that can be represented by the general formula $\left[\mathrm{M}_{1-x}{ }^{2+} \mathrm{M}_{x}{ }^{3+}(\mathrm{OH})_{2}\right]^{x+}$ $\left.\left[\mathrm{A}_{x / n}\right]^{n-} \cdot m \mathrm{H}_{2} \mathrm{O}\right]$ [6]. LDHs comprise brucite-like layers with divalent metal cations (e.g., $\mathrm{Mg}^{2+}, \mathrm{Fe}^{2+}, \mathrm{Co}^{2+}, \mathrm{Cu}^{2+}, \mathrm{Ni}^{2+}$, or $\mathrm{Zn}^{2+}$ ) coordinated octahedrally by hydroxyl groups. Isomorphic substitution by the trivalent metal cations (e.g., $\mathrm{Al}^{3+}$, $\mathrm{Cr}^{3+}, \mathrm{Ga}^{3+}, \mathrm{In}^{3+}, \mathrm{Mn}^{3+}$, or $\mathrm{Fe}^{3+}$ ) permits positively charged layers. In the above formula, value of $x$ is equal to the molar ratio $\mathrm{M}^{2+} /\left(\mathrm{M}^{2+}+\mathrm{M}^{3+}\right)$ and is generally in the range $0.2-0.4$; permutable inorganic or organic charge-compensating anions and water molecules lie in the interlayer region. In the LDH layers, each hydroxyl group is situated toward the region between the interlayer and maybe the interlayer anions and water molecules attached by hydrogen bonding [13]. However, the application of LDH for wastewater is restricted due to two reasons. Firstly, their little hydraulic conductivity in powdered or bulk forms through to the presence of compact layer stacking [14], and secondly, LDH exhibits little adsorption concerning cationic dyes [15]. Therefore, to enhance the adsorption performance of $\mathrm{LDH}$, toward cationic dyes, it was composited with hydrochar synthesized under hydrothermal carbonization conditions [14]. Similar composites such as carbon-dot-decorated LDH nanocomposites [16], Ni/ Fe layered double hydroxide (LDH) biochar composites [17], MgAl-LDH/biochar composites [18], and biochar with LDH for phosphorus recovery [14] are reported. All these and other related studies suggest superior sorption properties of composite over their single components. However, these blends are not studied for efficiency toward simultaneous removal of cationic and anionic molecules. This study is aimed at synthesis composite material of positively charged trimetallic $\mathrm{LDH}$ and carboxylates containing low-temperature hydrothermal carbon. The material synthesis is aimed for simultaneous removal of methylene blue (MB) as a cationic dye and methyl orange (MO) and reactive yellow-II (RY-II) as anionic dyes. All of these dyes are used in the local textile industry; therefore, their removal using a single material is of interest, as previously synthesized materials are reported to have the ability to remove single, that is, cationic or anionic dye.

\section{Materials and Methods}

2.1. Materials and Reagents. For the synthesis of LDH nitrates of $\mathrm{Co}, \mathrm{Al}$, and $\mathrm{Zn}$ and $\mathrm{NaOH}$ were obtained from UNICHEM Chemical Reagent Co., while HC was synthesized from glucose. $\mathrm{KNO}_{3}$ was obtained from LabChem, while $\mathrm{HCl}$ and $\mathrm{HNO}_{3}$ was from DAEJUNG Co. The cationic and anionic dyes were selected for sorption experiments (i.e., MB, MO, and RY-II), and all the solutions were prepared in deionized water. The $\mathrm{MB}$ dye was obtained from Fluka Co. and MO and RY from Merck Co., and used without further purification. Glucose for the preparation of hydrochar was obtained from Sigma Aldrich. All reagents used were of analytical grade. Structures of all three dyes are shown in Figure 1.

\subsection{Preparation of Adsorptive Composite Material}

2.2.1. Synthesis of HC. Carbonaceous material (hydrochar) was synthesized by hydrothermal carbonization of glucose (dextrose). Briefly, $1.0 \mathrm{~g}$ of glucose was added in $10 \mathrm{~mL}$ of deionized water in stainless steel reaction vessels with a Teflon lining tube. The Teflon tube was wrapped with Teflon tape and placed inside stainless steel autoclave with a volume capacity of $25 \mathrm{~mL}$. Finally, the vessel was closed and put into the microwave oven for $5 \mathrm{~h}$ at $200^{\circ} \mathrm{C}$. The reaction system was allowed to cool at room temperature [19]. The resulting $\mathrm{HC}$ was separated by centrifugation and washed with double distillted (DI) water until the $\mathrm{pH}$ became neutral (Figure S1). The hydrothermal carbonization process involves a multitude of concurring reactions, especially when it is performed using biomass therefore through the washing of the final product is very important. Hydrolysis is the first stage when biomass is degraded to monomers and oligomers with some intermediates (e.g., 5(hydroxymethyl)furfural and 2-furfural). The rate of hydrolysis is diffusion-controlled. Hydrolysis is followed by dehydration (loss of $\mathrm{OH}$ groups), decarboxylation, and decarboxylation, leading to loss of carboxyl $(\mathrm{COOH})$ and carbonyl $(\mathrm{C}=\mathrm{O})$ groups, respectively [20]. The initial $\mathrm{pH}$ was 3 ; therefore, the product was neutralized and then dried at $80^{\circ} \mathrm{C}$ in an oven overnight.

\subsubsection{Synthesis of Co-Al-Zn LDH. The LDH of Co-Al-Zn} was synthesized by coprecipitation method. Nitrate of Co, $\mathrm{Al}$, and $\mathrm{Zn}$, in the molar ratio 0.4:0.2:0.4 of the metals, respectively, were dissolved in deionized water, and the final volume was made up $100 \mathrm{~mL}$. The total concentration of metal ion solution was kept at $1.0 \mathrm{M}$. To this reaction mixture, freshly prepared $0.1 \mathrm{M} \mathrm{NaOH}$ solution was added with constant stirring until the $\mathrm{pH}$ become 9. After this, the reaction mixture was placed on a hot plate for $6 \mathrm{~h}$ at $60^{\circ} \mathrm{C}$ with homogenous stirring. After completion of the reaction, the surplus solution was removed, and the precipitate was washed with deionized water to remove impurities. The resultant product was dried in an oven overnight at $60^{\circ} \mathrm{C}$ and stored in a clean tube for characterization [21]. 
<smiles>CN(C)c1ccc(/N=N/c2ccc(S(=O)(=O)O[Na])cc2)cc1</smiles>

(a)

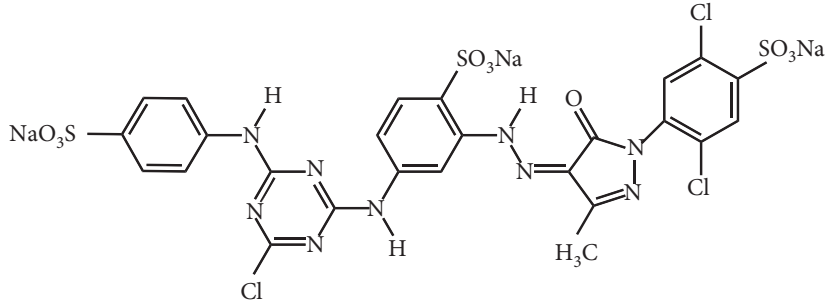

(b)<smiles></smiles>

(c)

Figure 1: Structures of selected dyes: (a) methyl orange, (b) reactive yellow-II, and (c) methylene blue.

2.2.3. Synthesis of HC: LDH Composite. The LDH:HC composite was also synthesized by coprecipitation method in different ratios (i.e., C-1, C-2, C-3, and C-4). For this, solution of Co-Al- $\mathrm{Zn}$ nitrate (in the molar ratio 0.4:0.2:0.4 in $100 \mathrm{~mL}$ ) was well mixed with $0.5,1.0,1.5$, and $2.0 \mathrm{~g}$ of $\mathrm{HC}$ (denoted as C-1 to C-4, respectively) and blended well by continuous stirring with the help of magnetic stirrer. To this reaction mixture, freshly prepared $0.1 \mathrm{M} \mathrm{NaOH}$ solution was added to maintain $\mathrm{pH}$ at 9 . After this, the reaction mixture was placed on a hot plate for $6 \mathrm{~h}$ at $60^{\circ} \mathrm{C}$ with homogenous stirring. Then obtained precipitate was washed, dried at $60^{\circ} \mathrm{C}$, and stored in clean tube for further characterization and dye removal.

2.3. Characterization of Composite Adsorbent. XRD analyses were performed on a Bruker-D2 phaser diffractometer, with CuKa radiation $(\lambda=1.5418 \AA$ ) $)$ with an operating voltage of $30 \mathrm{kV}$ and an operating current of $10 \mathrm{~mA}$. The surface functional groups of the adsorbent were determined by Fourier-transform infrared spectroscopy (Thermo Scientific Nicolet TM iS10), recorded from a wavenumber of $550-4,000 \mathrm{~cm}^{-1}$ under ATR mode. The specific surface area and pore size of the prepared material were determined by nitrogen adsorption using a surface area analyzer (Autosorb1 Quantachrome, ASiQwin). The sample was degassed under vacuum at $150^{\circ} \mathrm{C}$ for 24 hours before the measurement. The surface area of prepared materials was estimated by MBET (multipoint Brunauer-Emmett-Teller) method. The pore size distribution of prepared material was determined by the BJH (Barrett-Joyner-Halenda) model. The morphology of samples was examined by scanning electron microscopy (SEM), JeolLV-6490. The concentration of selected dyes was determined by a double-beam UV-visible spectrophotometer (Agilent Cary 100).

2.4. Adsorption Experiments. All the adsorption experiments were carried out in a $25 \mathrm{~mL}$ Erlenmeyer flask containing $15 \mathrm{~mL}$ of dye solution (MB, MO, and RY-II) of different initial concentrations, that is, $3.12,6.25,12.5$, and $25 \mathrm{mgL}^{-1}$ with $0.03 \mathrm{~g}$ of adsorbent by batch technique at $\mathrm{pH}$ 6.0. The resulting suspension was shaken thoroughly using a thermostat shaker working at $100 \mathrm{rpm}$ for $60 \mathrm{~min}$, and the supernatant liquid was separated by filtration. The absorbance of dyes in supernatant solutions of $\mathrm{MO}, \mathrm{MB}$, and RY-II before and after adsorption were determined by using a double-beam UV-visible spectrophotometer at 465, 665, and $566 \mathrm{~nm}$, respectively. The desired $\mathrm{pH}$ of the dyes was adjusted by adding $0.1 \mathrm{M} \mathrm{HCl}$ or $0.1 \mathrm{M} \mathrm{NaOH}$ solution. For the kinetic experiments, the above procedure was repeated at appropriate time intervals, and the supernatant liquid was separated by filtration. The percentage removal of dyes was calculated by using the following formula:

$$
\operatorname{Removal}(\%)=\left[\frac{\left(A_{0}-A_{e}\right)}{A_{0}}\right] \times 100,
$$

where $A_{0}$ and $A_{e}$ are the initial and final absorbance of dye solution before and after adsorption, respectively.

2.5. Determination of the Point of Zero Charge of the Adsorbent. The point of zero charge (PZC) of the adsorbent was determined using the batch equilibrium procedure [22]. A series of $100 \mathrm{~mL}$ conical flasks containing $45 \mathrm{~mL}$ of $0.1 \mathrm{M}$ $\mathrm{KNO}_{3}$ solution were adjusted at initial $\mathrm{pH}$ roughly between 2, $4,6,8,10$, and 12 by adding either $0.1 \mathrm{M} \mathrm{HNO}_{3}$, or $\mathrm{NaOH}$. The total volume of the solution in each flask was made exactly to $50 \mathrm{~mL}$ by adding $\mathrm{KNO}_{3}$ solution. The $\mathrm{pH}_{0}$ of the solutions were then accurately noted using a $\mathrm{pH}$ meter (Hanna pH 211 microprocessor). A $1.0 \mathrm{~g}$ of the adsorbent was added to each flask and was immediately capped. The suspension was then intermittently agitated for 24 hours. The $\mathrm{pH}$ values $\left(\mathrm{pH}_{f}\right)$ of the supernatant liquid were noted. The difference between the initial and final $\mathrm{pH}\left(\Delta \mathrm{pH}=\mathrm{pH}_{0}-\mathrm{pH}_{f}\right)$ values was plotted against the $\mathrm{pH}_{0}$. The point of intersection of the resulting curve on $\mathrm{pH}_{0}$ gave the PZC.

2.6. Experimental Design. The optimization of different variables was performed by using the statistical program, 
response surface methodology (RSM). Under RSM, the most widely used design is central composite design (CCD) [23]. $\mathrm{CCD}$ is applicable to evaluate the interaction between variables, and it is very a reliable, standard, and popular design to be used. This methodology performs a minimum set of experiments in an experimental matrix, improving statistical interpretation possibilities and indicating the interaction of parameters [24]. Experimental conditions for adsorption of dyes (MB, MO, and RY-II) were optimized for C-4 composite [25]. In this study, the effect of four independent variables on the removal of dyes was studied: amount of adsorbent $(X 1)$, volume $(X 2)$, concentration $(X 3)$ of each selected dye, and contact time (X4). The levels of such factors have been signed as $-1,0$, and +1 , respectively, for low, medium, and high levels shown in Table S1. After entering factors and levels in STATGRAPHICS Centurion $\mathrm{XVI}$, version software, 18 experiments were suggested in different conditions as shown in Table S2. At first, solutions of dyes were prepared with required concentrations and poured in $50 \mathrm{~mL}$ Erlenmeyer flask, then added the required amount of adsorbent for the given volume, and agitated in the thermostat shaker at $100 \mathrm{rpm}$ for the desired time period. Then, samples were filtered, and their absorbance was recorded by UV-vis spectrophotometer.

\subsubsection{Statistical Analysis and Validation of the Experimental} Model. The quality of the developed model was checked by analysis of variance (ANOVA); the responses and the corresponding parameters have been modeled and optimized using ANOVA, which has been used to identify significant variables and their individual and interactive effects on the removal of dyes. Intrinsically, the optimization process involves three substantial steps, which are performing the statistically designed experiments, estimating the coefficients in a mathematical model and predicting the response, and checking the adequacy of the model. The quality of fit of the polynomial model was expressed by the coefficient of determination $\left(R^{2}\right)$. The significance of process variables was checked by $p$ value and $F$ value [25].

\subsection{Desorption and Recyclability Test. $3,0^{-1}$}

To evaluate the applicability of LDH:HC composite in practical water treatment, the desorption and recyclability of composite materials in dyes removal were evaluated. For desorption of dyes from the surface of the composite material, six portions, each $300 \mathrm{mg}$ of material was first agitated (at $100 \mathrm{rpm}$ ) with $10 \mathrm{~mL}$ of $50 \mathrm{mg} \mathrm{L}^{-1}$ dye solution for $1 \mathrm{hr}$. After equilibrium has reached, all six material portions were filtered and agitated separately with $0.5 \mathrm{M} \mathrm{NaHCO}, 0.1 \mathrm{M}$ $\mathrm{NaOH}, 0.1 \mathrm{M} \mathrm{HCl}$, ethanol, methanol, and $0.01 \mathrm{M} \mathrm{NaOH}$ in methanol. The concentration of dye solution stripped out from adsorbent material was determined, and recovery (desorption) was calculated using equation (2).

The results showed that all three dyes detach better from the adsorbent by using $0.01 \mathrm{M} \mathrm{NaOH}$ in methanol. Thus, for recycling, the dye adsorption experiment in Section 2.4 was repeated. And further desorption is performed by using $0.01 \mathrm{M} \mathrm{NaOH}$ in methanol. Six cycles of adsorption test were carried out, analyzing the amount recovered, referring to the following equation:

$$
\text { Desorption }(\%)=100 *\left(\frac{\text { released dye }}{\text { retained dye }}\right) \text {. }
$$

\section{Results and Discussion}

3.1. Visual Appearance. As seen from Figure S2, the synthesized LDH was pink in color whereas the increasing amount of HC into LDH changed the color of LDH:HC composites into brown and finally into deep brown-black. The color change indicates the incorporation of $\mathrm{HC}$ into $\mathrm{LDH}$. This observation was explored using various characterization techniques and discussed below in detail.

3.2. Characterization. The $\mathrm{LDH}$ of $\mathrm{Co}-\mathrm{Al}-\mathrm{Zn}, \mathrm{HC}$, and their composites in different ratios (i.e., C-1 to C-4) were characterized by PXRD. Figures $2(\mathrm{a}-\mathrm{f})$ show the diffractogram of pure $\mathrm{HC}$ with broad reflections at $2 \theta$ value of 18.9 with the diffraction of (002) plane corresponding to the amorphous structure of HC [26]. Figure 2(a) is the XRD pattern of LDH that shows sharp and symmetrical peak appearing at $2 \theta$ value of $11.08,22.5,31.5,34,38.5,46$, and 56 , which correspond to diffraction of the $(003,006,009,012,015,018$, and 110) planes. This revealed that the synthesized LDH was well crystallized and had a layered structure with $R_{3} m$ rhombohedral symmetry [1]. The peaks that appear at a $2 \theta$ value of 36 with the diffraction of 101 plane may be attributed to the presence of $\mathrm{ZnO}$ [27]. Moreover, Figures 2(b)-(e) are HC:LDH composites that exhibit similar $2 \theta$ values but show a decrease in peak intensities and then disappear at $009,012,015$, and 018 . The systematic shift to lower $2 \theta$ values and disappearance of few peaks suggest poor long-range ordering of $\mathrm{LDH}$. Therefore, it may be assumed that $\mathrm{HC}$ gets filled into the interlayers of $\mathrm{LDH}$ and disrupts the layering of $\mathrm{LDH}$ and on increasing $\mathrm{HC}$ concentration a new layered material evolves with $\mathrm{HC}$ into the layers. Our idea is supported by interlayers spacing or basal spacing $(d)$ [28], which was calculated by using Bragg's equation (2) shown in Table 1.

$$
d=\frac{\lambda}{2 \sin \theta},
$$

where $d$ is the basal spacing, $\theta$ is the diffraction angle, and $\lambda$ is the wavelength.

FTIR spectra of all materials (HC, C-1 to C-4, and LDH) are shown in Figure 3. The spectral peaks range between 4,000 and $550 \mathrm{~cm}^{-1}$. FTIR spectral peaks for HC appear in the region at $3,200-3,500 \mathrm{~cm}^{-1}$ that shows $\mathrm{O}-\mathrm{H}$ stretching vibration; this was the primary functional group in $\mathrm{HC}$. The peak that appears at $2,915 \mathrm{~cm}^{-1}$ is due to $\mathrm{C}-\mathrm{H}$ stretching vibration, while carboxyl groups display that peaks at $1,617 \mathrm{~cm}^{-1}$ attribute to $\mathrm{C}=\mathrm{C}$ stretching vibrations. The peak at $1,718 \mathrm{~cm}^{-1}$ ascribed to the symmetric stretching vibration of the carboxylic group -COO- [26]. The peak below $1,000 \mathrm{~cm}^{-1}$ is attributed to the deformation of $\mathrm{C}-\mathrm{H}$ out of plane bending vibration in aromatic compounds [19]. The 


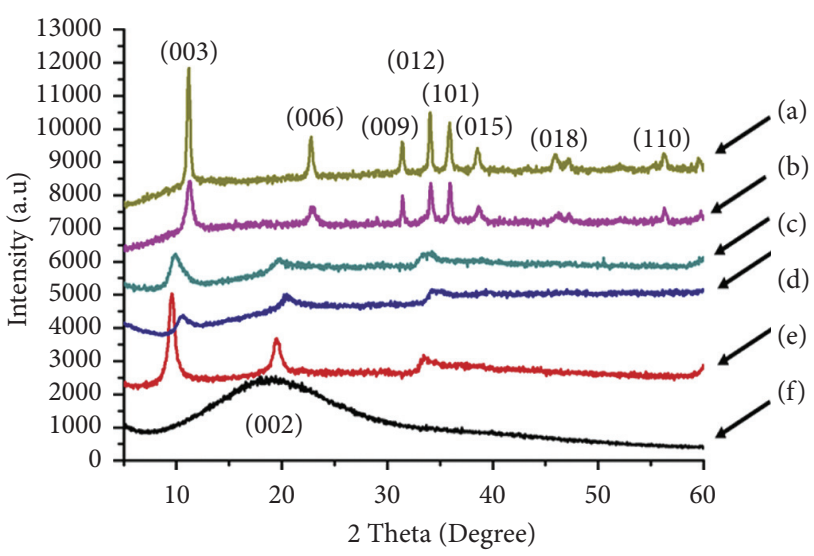

Figure 2: X-ray diffractogram of LDH (a), 0.5 HC:LDH (b), 1.0 HC:LDH (c), 1.5 HC:LDH (d), 2.0 HC:LDH (e), and HC (f).

TABLE 1: Impact of HC content on basal spacing and shift in $2 \theta$ value.

\begin{tabular}{lcc}
\hline Materials & $2 \theta\left(^{\circ}\right)$ & Basal spacing, $d(\mathrm{~nm})$ \\
\hline LDH & 11.12 & 2.27 \\
C-1 & 11.04 & 0.23 \\
C-2 & 9.98 & 0.16 \\
C-3 & 10.3 & 0.17 \\
C-4 & 9.45 & 0.15 \\
\hline
\end{tabular}

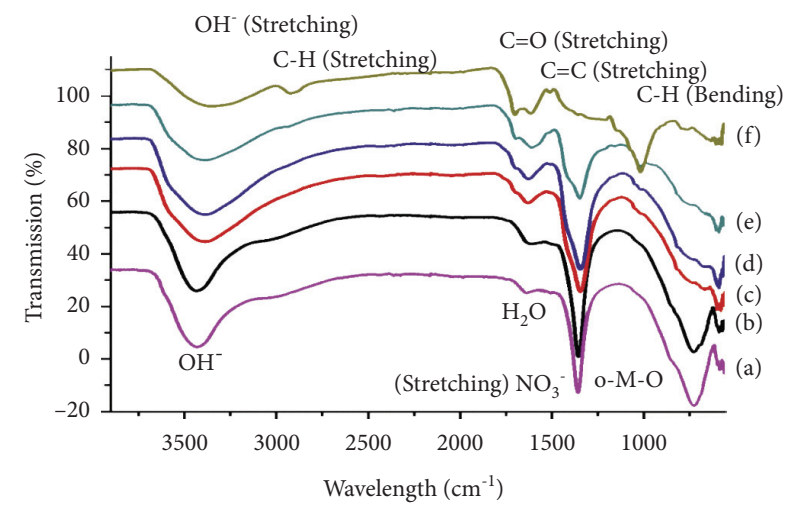

Figure 3: FTIR spectra LDH (a), C-1 (b), C-2 (c), C-3 (d), C-4 (e), and $\mathrm{HC}(\mathrm{f})$.

broad band around $3,448 \mathrm{~cm}^{-1}$ assigned to stretching and bending vibrations of $-\mathrm{OH}$ group lying within the layer of LDH brucite and an interlamellar water molecule. While broadening of the band is due to the formation of the hydrogen bond. The strong band that appears at $1,362 \mathrm{~cm}^{-1}$ is due to the stretching vibration of the $\mathrm{NO}_{3}{ }^{-}$group in the $\mathrm{LDH}$ interlayer. The peaks at $3,448 \mathrm{~cm}^{-1}$ and $1,362 \mathrm{~cm}^{-1}$ reduce their sharpness with an increase of the amount of $\mathrm{HC}$ in composite because $\mathrm{HC}$ is taking their places within $\mathrm{LDH}$ sheets. The bands between 725 and $570 \mathrm{~cm}^{-1}$ were designated to $\mathrm{O}-\mathrm{M}-\mathrm{O}$, vibrations in the layers, and translational motion of $\mathrm{Zn}-\mathrm{OH}$. The peak around $1,637 \mathrm{~cm}^{-1}$ indicated the bending vibration of interlayer water molecules [29]. These results confirm the presence of a variety of functional groups, which could attract dyes molecules of both positive and negative charge.

Figure 4(a) reveals the $\mathrm{N}_{2}$ adsorption-desorption isotherms, and Figure 4(b) shows pore size distribution of $\mathrm{LDH}, \mathrm{HC}$, and their composite. The $\mathrm{LDH}$ exhibits an $\mathrm{N}_{2}$ isotherm resembling type IV isotherm (in the IUPAC classification) with one clear H3-type hysteresis loop, which indicates aggregates of LDH forming slit-like pores. The surface area and porous properties of $\mathrm{LDH}, \mathrm{HC}$, and their composite are summarized in Table 2. It can be seen that the MBET surface area of LDH was $19.385 \mathrm{~m}^{2} \mathrm{~g}^{-1}$, and pore volume was $0.044 \mathrm{cc} \mathrm{g}^{-1}$, after the addition of $0.5 \mathrm{~g} \mathrm{HC}$. The MBET surface area and pore volume increased and become $46.986 \mathrm{~m}^{2} \mathrm{~g}^{-1}$ and $0.133 \mathrm{cc} \mathrm{g}^{-1}$; this increase in the surface area shows additional effect resulting from adding two porous materials. Then further increase in the amount of $\mathrm{HC}$ into LDH leads to a decrease in surface area and pore volume gradually from $2.622 \mathrm{~m}^{2} \mathrm{~g}^{-1}$ to $0.043 \mathrm{~m}^{2} \mathrm{~g}^{-1}$ and pore volume from 0.010 to $0.00 \mathrm{cc} \mathrm{g}^{-1}$. It may be due to the process of composite formation where the pores of LDH may get covered, filled, or partially blocked by the HC. The above data show that the HC becomes the part of LDH sheets, which result in a significant change in the porosity [30].

SEM images of various materials are shown in Figure 5. LDH particles were agglomerated and possessed lumpy particles, while on the addition of $0.5 \mathrm{~g} \mathrm{HC}$, the particle size was increased and then decreased gradually from a composite containing $1.0 \mathrm{~g} \mathrm{HC}$ to a composite containing $2 \mathrm{~g}$ HC. EDX analysis (Figure S3) shows that the LDH contains $\mathrm{Zn}$-Al-Co as elements, whereas $\mathrm{HC}$ contains $\mathrm{C}$ and $\mathrm{O}$, while their composites contain $\mathrm{Zn}$-Al-Co along with $\mathrm{C}$ and $\mathrm{O}$. This result indeed confirms that the HC was homogeneously integrated with LDH. The data suggest the formation of composite with reduced porosity and decreased in overall particle size as compared to parent materials. Figure 6 summarizes the findings of the characterization study that the structure of LDH:HC composite is formed by metal cation coordinated octahedrally by hydroxyl groups, resulting octahedral share their edges to form infinitely large layers that it is typically called LDH [13]. When a small amount of $\mathrm{HC}$ is added in mixture during formation of LDH, it stucks onto LDH sheets which explains large surface area of the composite.. eA decrease in surface area was observed when HC content was increased because added $\mathrm{HC}$ arrangesitselves between LDH sheets.

\subsection{Simultaneous Removal of Selected Dyes}

3.3.1. Selection of Adsorptive Composite. The prepared HC, $\mathrm{LDH}$, and their composites in different ratios (C-1 to C-4) were tested for adsorption of cationic and anionic dyes $(\mathrm{MB}$, MO, and RY-2). The results are shown in Figure 7. This shows that the composite C- 4 containing $2.0 \mathrm{~g}$ of $\mathrm{HC}$ is the most effective for simultaneous removal of three dyes. Furthermore, $\mathrm{pH}$-dependent behavior of all six materials and selected dyes was investigated by correlating the point of zero charge (PZC) on sorbent and uptake of dyes.

The point of the zero charge (PZC) and the pKa (MB, $\mathrm{MO}$, and RY-II) of the dyes were used to study the effect of 


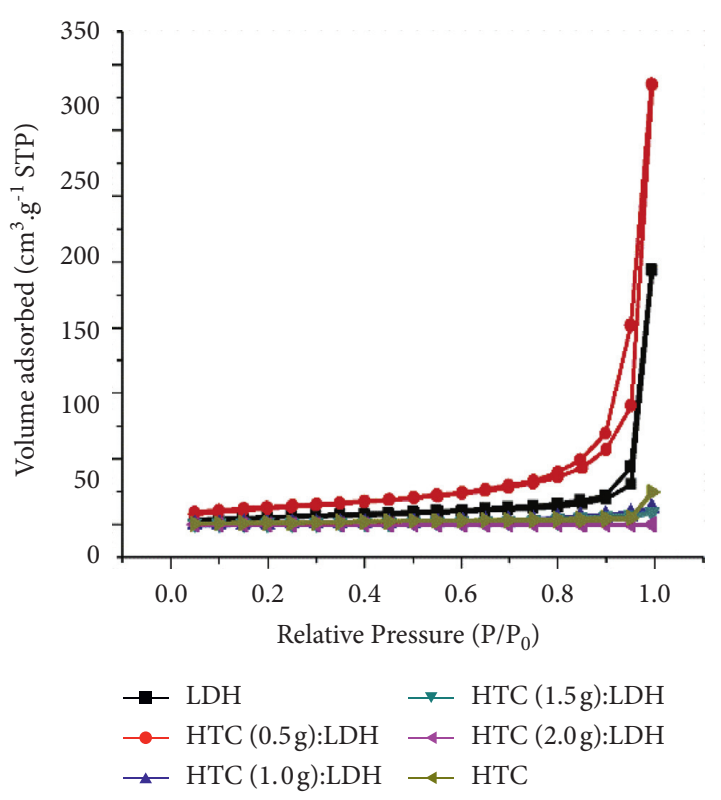

(a)

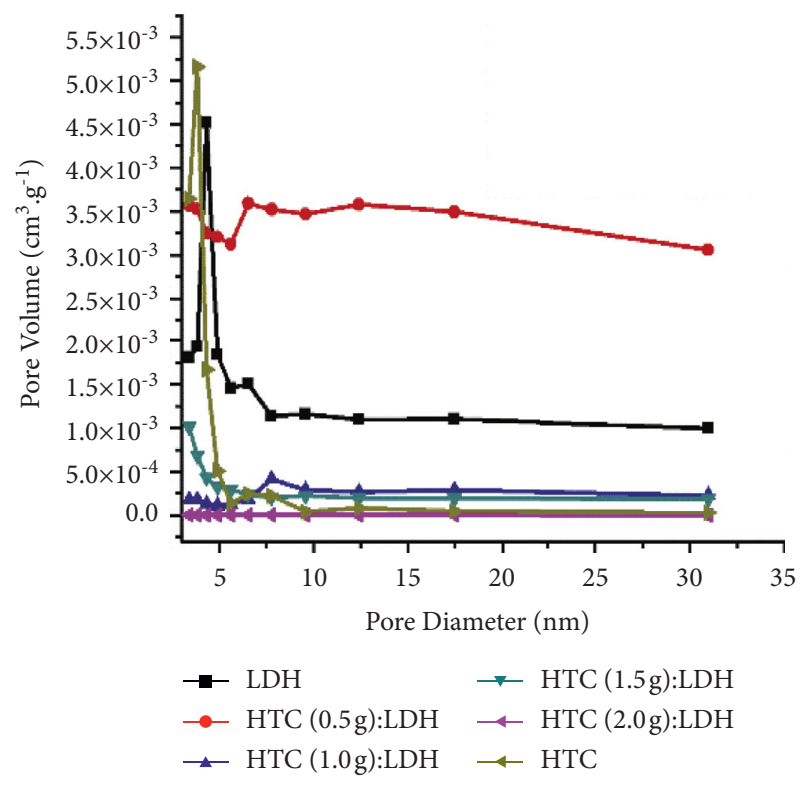

(b)

FIgURE 4: $\mathrm{N}_{2}$ adsorption-desorption isotherm (a) and pore size distribution (b) of various materials (LDH, C-1 to C-4, and HC).

TABLE 2: Porosity data of various materials as obtained through nitrogen adsorption porosimetry.

\begin{tabular}{lccc}
\hline Sample name & Surface area $\left(\mathrm{m}^{2} \mathrm{~g}^{-1}\right)$ & Pore diameter $(\mathrm{nm})$ & Pore volume $\left(\mathrm{ccg}^{-1}\right)$ \\
\hline LDH & 19.385 & 4.325 & 0.044 \\
C-1 & 46.986 & 3.405 & 0.133 \\
C-2 & 2.622 & 7.790 & 0.010 \\
C-3 & 2.847 & 3.053 & 0.007 \\
C-4 & 0.043 & 3.053 & 0.000 \\
HC & 3.874 & 3.426 & 0.008 \\
\hline
\end{tabular}

the $\mathrm{pH}$ solution on the adsorption of the dyes. PZC can be used as a qualitative parameter for an adsorbent surface charge at specific $\mathrm{pH}$ at which the net total particles load is zero. The synthesized $\mathrm{LDH}$ (C-1 to $\mathrm{C}-4)$ and their composites showed PZC at 6 , while it was 5 for HC's. Along with the positive charge, due to the structure of the LDHs and the negative charge on the surface of the $\mathrm{HC}$, the samples have variable charges caused by the interactions of ions such as $\mathrm{H}^{+}$or $\mathrm{OH}^{-}$from the solution. For $\mathrm{pH}$ values below $\mathrm{PZC}$, the hydrated surface of $\mathrm{LDH}, \mathrm{HCs}$, and composites are protonated and positively charged. The surface of $\mathrm{LDH}, \mathrm{HC}$, and its composites is deprotonated at $\mathrm{pH}$ values above $\mathrm{PZC}$ and remains negatively charged. Dissociation constant for $\mathrm{MO}$, RY-II, and MB in the aqueous solution is 3.46, 3.8, and 5.3, respectively (Kim and Kan, 2015), and all these molecules existed as monovalent ions predominantly above this $\mathrm{pH}$ value. At $\mathrm{pH}$ values below the $\mathrm{PZC}$ of $\mathrm{LDH}$ and their composite above their $\mathrm{pKa}$, there are two possible processes for dye adsorption to $\mathrm{LDH}$, one of which is the replacement of the intermediate layer $\mathrm{OH}^{-}$with the dye types. The other is the adsorption through the relationship between positively charged LDH surface and negatively charged surface and dye anions or cations on HC's (Mahjoubi et al., 2016). For pH values above $\mathrm{PZC}$, higher adsorption increase as $\mathrm{pH}$ rises can be attributed to surface charge and the presence of binding sites on the surface of composites that arose from $\mathrm{LDH}$ (Zhao et al. 2011). In Figure 8(f), adsorption of MB (cationic) dye is preferred when the $\mathrm{pH}$ of the solution is higher than PZC solutions, while adsorption of anionic dyes (MO and RY-II) is preferred at lower pH (Silva et al., 2015). This study suggests that $\mathrm{C}-4$ at $\mathrm{pH} 6$ is suitable for simultaneous removal of three selected dyes, so more optimization studies have been conducted using C-4 composite material as an adsorbent.

3.3.2. Operating Variables Optimization. Optimization was performed using a simultaneous variation of operating variables that may affect the uptake of dyes onto C-4 sorptive material. Central composite design using with the total of 18 runs for optimization of four experimental variables was used. Table S3 shows the optimization data, whereas Tables S4-S6 show the effect of interactive terms on removal efficiency for all three dyes. The lower the $p$ and higher the $F$ value, the more significant effect a term has on removal efficiency. Model fitting and validation data is provided in a supplementary sheet of this manuscript (Figure S4). The removal (\%) of selected dyes was more than $80 \%$ for all dyes at certain 

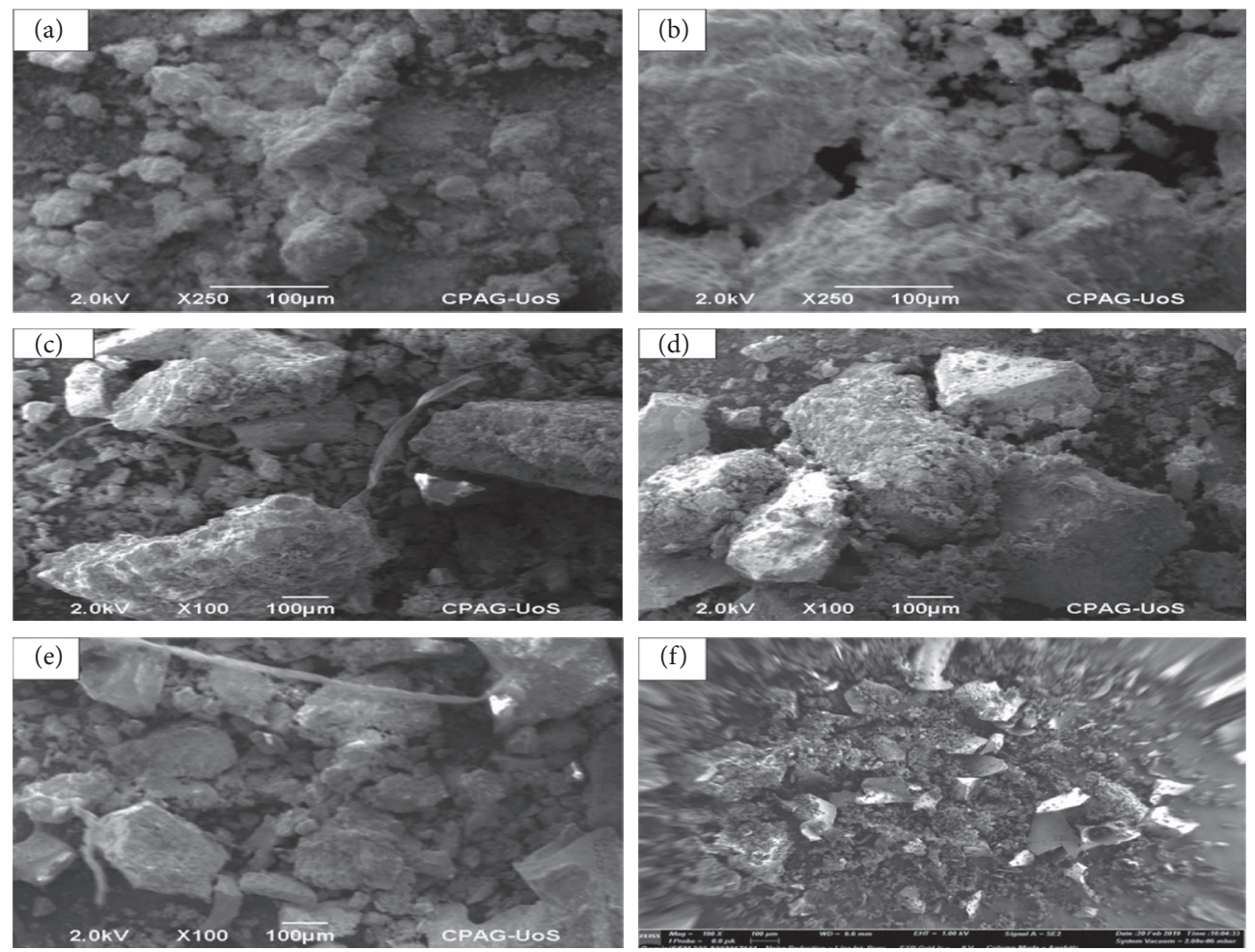

Figure 5: SEM images of LDH (a), C-1 (b), C-2 (c), C-3 (d), C-4 (e), and HC (f).

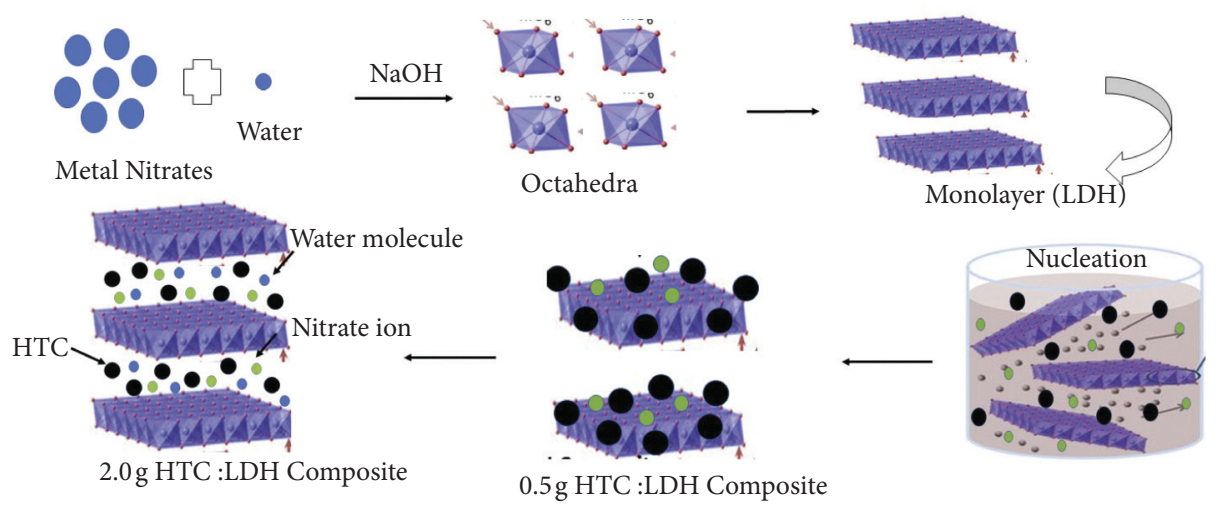

Figure 6: Pictorial representation of synthesized composite.

conditions. The lowest removal (\%) for MB, MO, and RY-II dyes are 34,57 , and $31 \%$. This reveals that uptake of dyes on C-4 depends upon the chemical environment in the solution. Furthermore, Pareto analysis gives more significant information to interpret the results. Details on Pareto charts are provided in a supplementary material (Figure S4). Pareto graphic analysis revealedthe dependancy of removal of $\mathrm{MB}$ dye on concentration. It was obsereved that increasing in concentration resulted in the reduction of the sorption. In the case of $\mathrm{MO}$, concentration and time were found to be most significant, and an inverse relationship is predicted toward sorption. However, RY-II dye showed different behavior; increasing concentration and amount together resulted in higher sorption, but an increase in concentration and time would negatively impact the sorption.
(1) Statistical Analysis and the Model Fitting. RSM is more advantageous than the traditional single-variable optimization in that it saves time, space, and raw material. After optimizing four experimental operating variables, there checked the reliability of the model by ANOVA analysis. The ANOVA for adsorption study of MO, MB, and RY-2 was used in order to confirm the goodness of the models. The significance of each term is presented in Tables S4-S6. Table S4 shows the significance of each independent variable on removal as well as the effect of the interaction of different variables. Significance can be determined by the corresponding $F$ and $p$ value. Greater $F$ and lesser $p$ values mean the more significant effect, for example, Table S4 shows that the $F$ ratio for term concentration is 251.98 and its $p$ value is 0.0005 ; therefore, concentration have a 


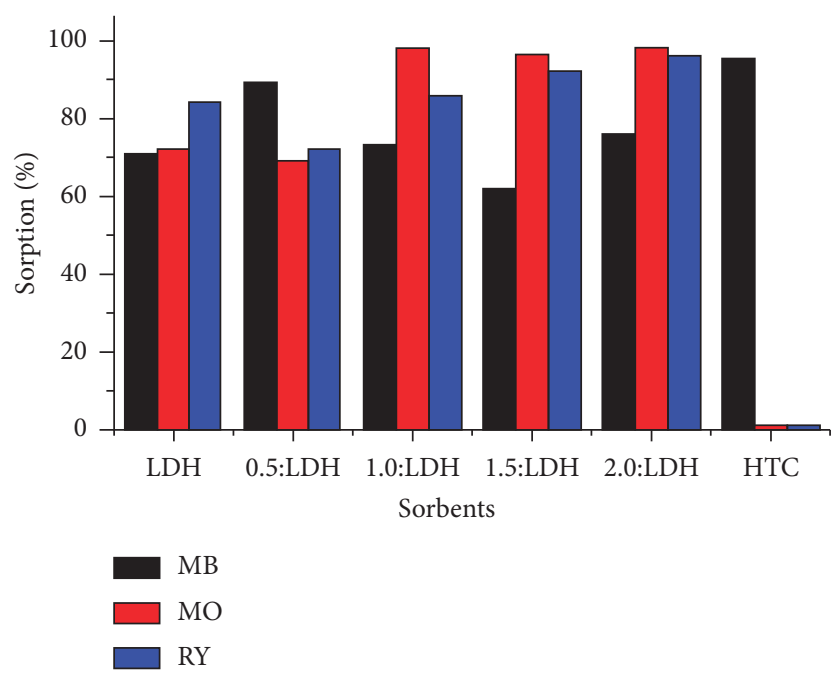

Figure 7: Adsorption of selected dyes onto various prepared materials (LDH, C-1 to C-4, and HC). Operating conditions: $20 \mathrm{~mL}$ of dye solution (i.e., $50 \mathrm{mg} \mathrm{L}^{-1}$ ), $1.5 \mathrm{~g} \mathrm{~L}^{-1}$ of adsorbent, and $60 \mathrm{~min}$ of stirring at $100 \mathrm{rpm}$.
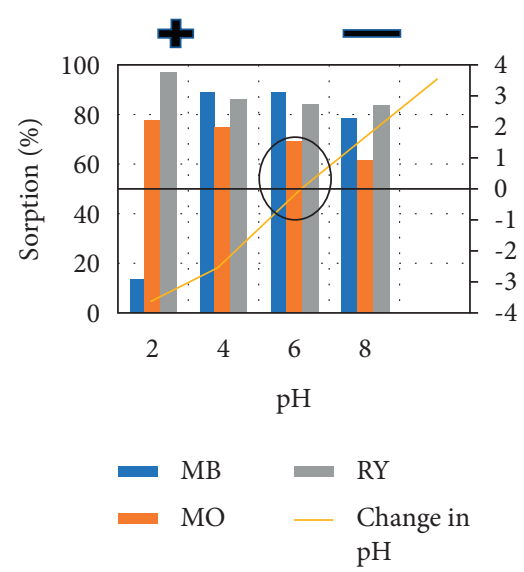

(a)
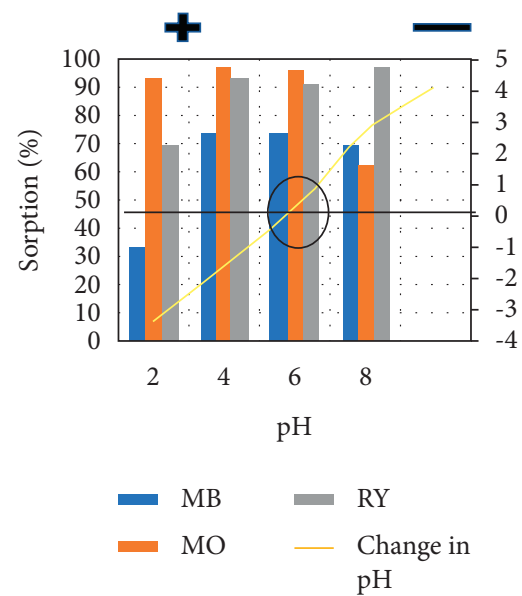

(d)
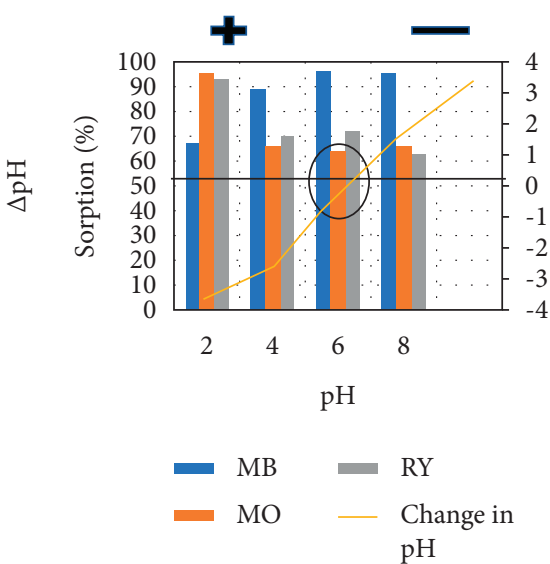

(b)
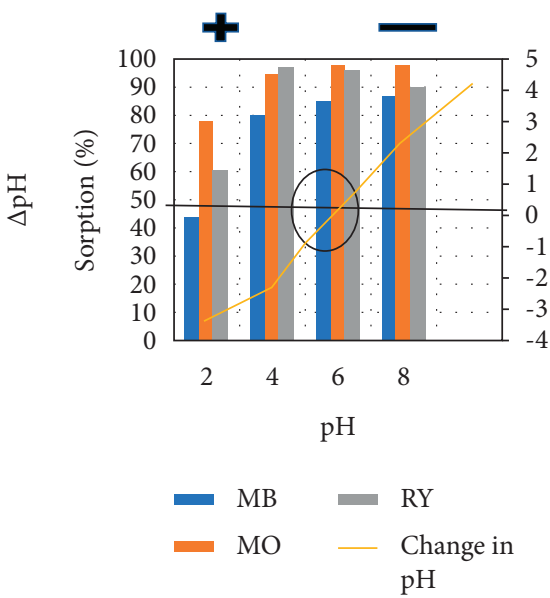

(e)
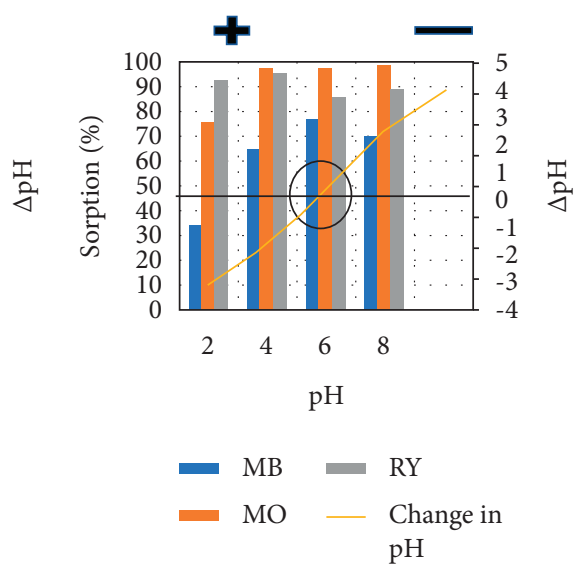

(c)
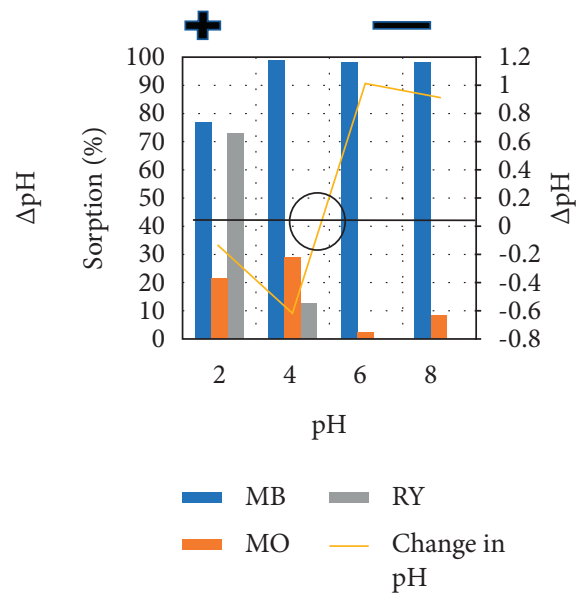

(f)

FIGURE 8: Point of zero charge plots and adsorption behavior of various materials for selected dyes. LDH (a), C-1 to C-4 (c-d), and HC (e). 
significant effect on removal of dye. Other important terms are amount and interaction term $\mathrm{BD}$, that is, volume and time.

In the above three models, $p$ values are less than 0.05 , which indicates that regressions are significant at a $95 \%$ confidence level. It implies that the models are significant and can appropriately explain the relationship between responses and independent variables. The quadratic model is found to be more significant than other models for $R$ response [25].

Goodness-of-fit for the model was also evaluated by coefficients of determination $R^{2}$ (correlation coefficient) and adjusted coefficients of determination, $R^{2}$ adj (Sarrai et al., 2016). The large value of the correlation coefficient $R^{2}=99.389,99.86$, and 99.74 indicated high reliability of the model in predicting the removal (\%) of dyes, that is, $\mathrm{MB}$, $\mathrm{MO}$, and RY, respectively.

(2) Pareto Chart Analysis. Thus, this analysis calculates the effect of each factor on the response, according to the following relation:

$$
P i=\frac{b i^{2}}{\sum b i^{2}}, \quad i \neq 0 .
$$

The Pareto graphic analyses are shown in Figures 9(a)9(c) and were used to find an association between the variables that are statistically significant. Bars that cross the reference line are significant. The negative sign on the chart shows inverse relationship, while a positive sign shows a direct relationship between independent variables. The results in Figure 9(a) suggested that concentration $(C)$ is negatively significant and amount $(A)$ is positively significant, while the interaction of volume $(B)$ versus time $(D)$ and amount $(A)$ versus volume $(B)$ are positively significant. The chart in Figure 9(b) shows that the interaction between concentration versus time and volume versus time is negatively significant, while interaction between amount versus concentration and volume is positively significant. The chart in Figure 9(c) demonstrates that the interaction between amount versus volume and concentration, and also concentration versus time is positively significant, while the interaction between volume and concentration is negatively significant. These results are in agreement with ANOVA analysis.

3.3.3. Effect of Process Variables. In order to examine the interactions between the factors and responses, three-dimensional (3D) response surface plots are very helpful showing a function of two factors maintaining the other factor at a fixed level [25].

The effect of the four different independent process variables including the amount of adsorbent, volume of dye, concentration, and time on removal efficiency $(R)$ are shown in the 3D response surface plots (Figures 9(a)-9(h)). The mutual effect of volume of MB with time and amount was shown in Figures 9(a) and 9(b). Diagram (a) pointed out that the removal efficiency of MB dye decreased with an increase in volume from 10 to $50 \mathrm{~mL}$ and increased with increasing time from 10 to $120 \mathrm{~min}$. Diagram (B) shows that the removal of MB dye is relatively stable or slightly increased at variable amount and removal is slightly decreased by increasing volume from 10 to $30 \mathrm{~mL}$ and then increased from 40 to $50 \mathrm{~mL}$. The data suggest that $\mathrm{MB}$ can be effectively removed at lower concentrations, whereas material can handle larger volumes at increased contact time.

Diagram (c) represent the effect of removal (\%) with the amount, volume, and concentration of MO dye; it can be seen in Figure 9(c) that the amount has no significant effect on removal, but the removal of $\mathrm{MO}$ dye increases with increasing volume from 10 to $50 \mathrm{~mL}$. MO can be removed at any concentration level and using even larger volumes.

Figures 9(e)-9(h) show the effect of amount, volume, concentration, and time on the removal of RY-II dye. Figure 9(e) shows the mutual effect of sorbent amount and dye concentration on removal, and it was observed that the removal is increased by decreasing of the adsorbent amount and by increasing of dye concentration. Thus, the removal of RY-II is possible at increased concentration and the small amount of sorbent. The removal is efficient at larger volumes, and contact time has a positive impact.

Figure 9(f) shows the mutual effect of amount and volume on the removal of RY-II, and it was found that removal is increased by decreasing amount and increased by increasing volume. Figure $9(\mathrm{~g})$ shows the mutual effect of concentration and time on removal, and the graph shows that the increasing concentration has no effect on dye removal, but removal is increased by increasing sorption time. Figure $9(\mathrm{~h})$ shows the mutual effect of volume and time on dye removal, and it can be supposed that the removal is increased by decreasing solution volume and increasing time.

\subsubsection{Optimum Conditions for Simultaneous Removal of} Dyes. Table 3 shows the optimum conditions for removal of all three dyes as predicted through the model, and it can be seen that optimum removal of dyes is predicted at slightly different experimental conditions; for example, it is predicted that maximum removal for $\mathrm{MB}, \mathrm{MO}$, and RY-2, respectively, can be obtained using 312,258 , and $278 \mathrm{mg}$ of composite material. Therefore, for simultaneous validation, a new set of conditions (close to all) were selected and tested experimentally. Values close to predicted ones confirm the accuracy of the model. Data shows that $300 \mathrm{mg}$ of sorbent can effectively clean $10 \mathrm{~mL}$ of effluent with a contact time of 60 minutes at a concentration of up to $50 \mathrm{mg} \mathrm{L}^{-1}$ of each dye. Furthermore, optimized values were applied to the real samples to check the applicability of the current method. The samples of wastewater were collected from the textile industry, Karachi, Pakistan. The removal (\%) of dyes from industrial wastewater was achieved about $80 \%$, while the removal (\%) of the mixture of three dyes was $97.6 \%$ (Table 3).

\subsection{Equilibrium Studies}

3.4.1. Modelling of Sorptive Reaction through LangmuirFreundlich Isotherms (LF Isotherm). Both homogenous and heterogeneous binding surfaces can be modeled by using 


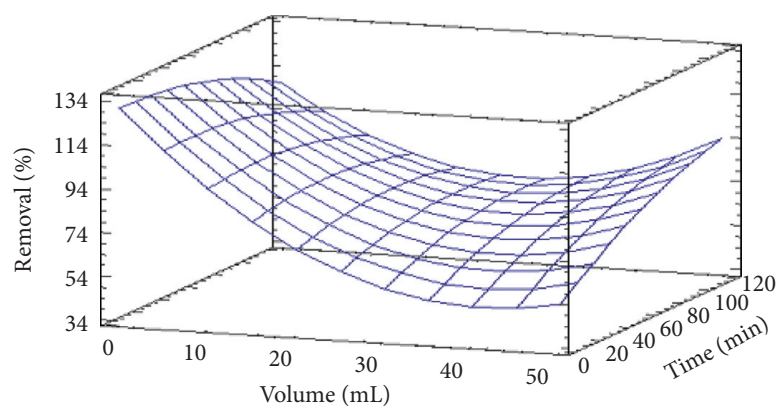

(a)

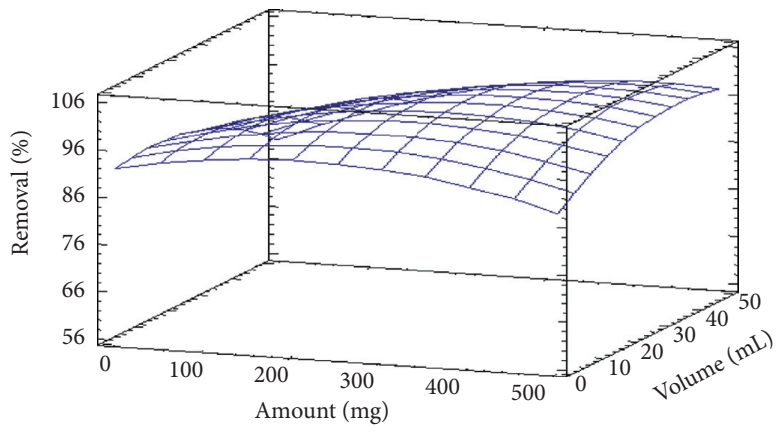

(c)

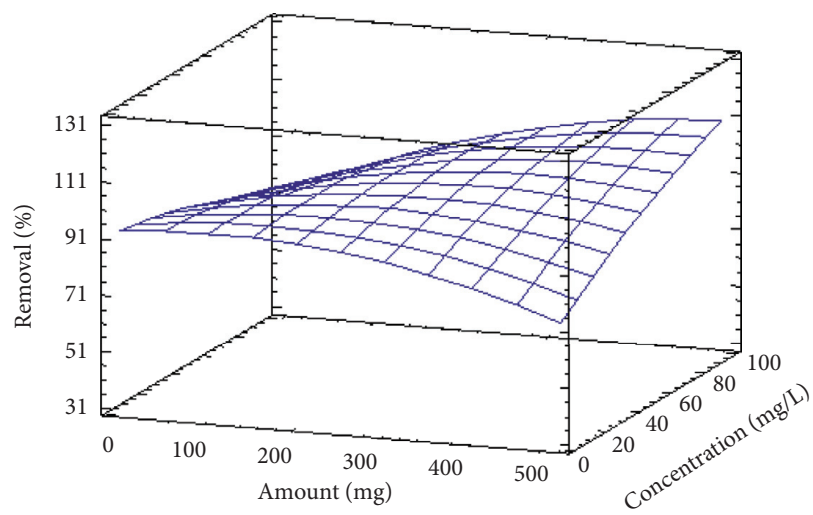

(e)

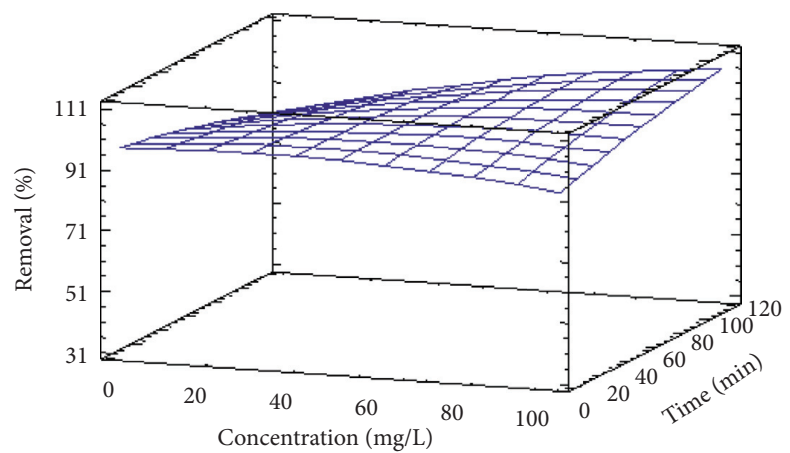

(g)

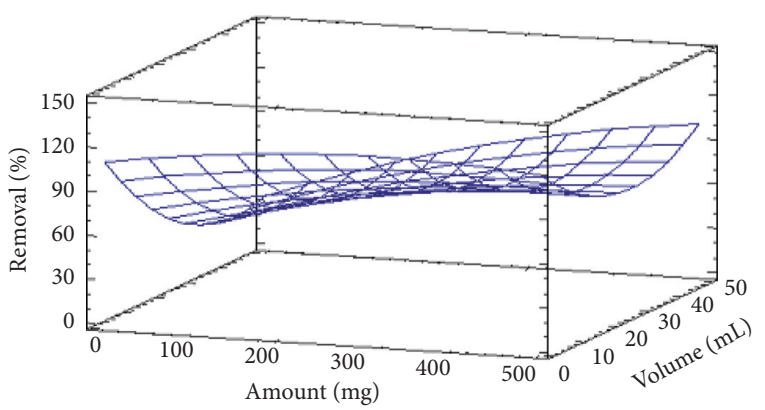

(b)

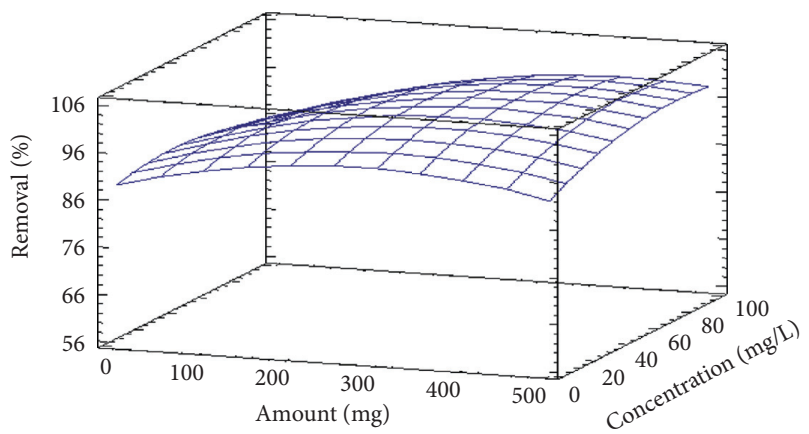

(d)

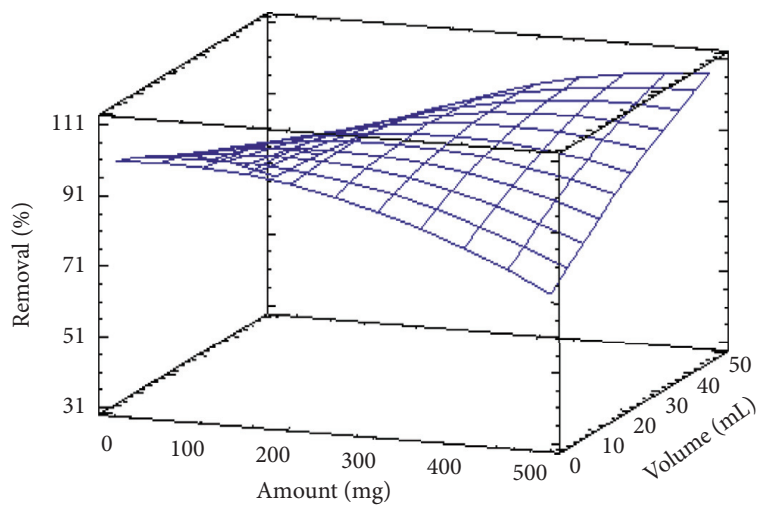

(f)

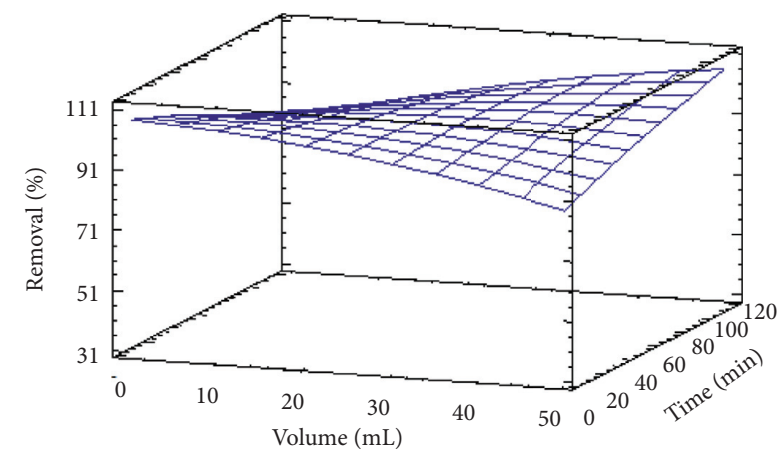

(h)

FIgURE 9: 3D response surface plots for MB ( $\mathrm{a}$ and b), MO (c and d), and RY-2 (e-h).

Langmuir-Freundlich isotherm (LF binding model, equation (5)), which defines the relationship of bound $(B)$ and free $(F)$ guest in heterogeneous systems with three fitting coefficients: $N_{t}, a$, and $m$ under equilibrium conditions (where $N_{t}$ is the total number of binding sites or adsorption capacity and $a$ is median binding affinity $\left(K_{0}\right)$ and may be calculated using relationship $K_{0}=a^{1 / m}$ ). The " $m$ " term defines heterogeneity index, which varies from 0 to 1 , where 
TABLE 3: Optimum conditions for simultaneous removal and application to real wastewater samples.

\begin{tabular}{|c|c|c|c|c|}
\hline \multirow{2}{*}{ Factors } & \multicolumn{3}{|c|}{ Optimum values } & \multirow{2}{*}{ Chosen values for simultaneous removal } \\
\hline & MB & MO & RY-2 & \\
\hline Amount (mg) & 312 & 258 & 278 & 300 \\
\hline Volume $(\mathrm{mL})$ & 10 & 31 & 30 & 10 \\
\hline Concentration $\left(\mathrm{mgL}^{-1}\right)$ & 45 & 56 & 56 & 50 \\
\hline Time (min) & 67 & 66 & 63 & 60 \\
\hline & \multicolumn{4}{|c|}{ Removal (\%) } \\
\hline Predictive & & & & \\
\hline Experimental & 99 & 98 & 99 & 97.6 \\
\hline
\end{tabular}

the value of $m=1$ shows that the material is homogenous and $m<1$ shows that the material is heterogeneous.

$$
B=\frac{N_{t} a F^{m}}{1+a F^{m}}
$$

The LF fitting parameters were calculated from experimental data using solver function in MS Excel keeping the square sum of the error to minimum and changing fitting coefficients, that is, $N_{t}, a$, and $m$ as shown in Table 4 . In this study, LF isotherm was applied to understand the behavior of composite sorbent for various dyes over wide concentration regimes that span both saturation and subsaturation regions. The fitness of the L-F isotherm is graphically shown in Figure S3. The high value of $N_{t}$ for MB suggests more number of binding sites onto the adsorbate, but it shows poor binding affinity (0.0018) as compared to MO and RY-II dyes. Also, the material provides a heterogeneous surface for MB (value of $m$ is less than 1.0) whereas homogenous for $\mathrm{MO}$ (value close to 1.0) and cooperative adsorption type for RY-II [31]. The isotherm results also suggest that composite can offer multiple types of interactions for simultaneous removal of dyes with variable charges and polarity.

DR isotherm was employed to understand the type of interactions responsible for uptake of dyes using the following equation, which was fitted to data, and various fitting parameters were calculated and are shown in Table 4:

$$
\begin{aligned}
\ln \text { Cads } & =\ln X m-\beta \varepsilon^{2}, \\
\varepsilon & =R T \ln \left(1+\frac{1}{C e}\right), \\
E & =\frac{1}{\sqrt{-2 \beta}},
\end{aligned}
$$

where Cads is the quantity of dye uptake unit mass of composite, $X m$ and $\beta$ are D-R constants, $\varepsilon$ is Polanyi potential, $R$ is gas constant $\left(8.31 \mathrm{~J} \mathrm{~mol}^{-1} \mathrm{k}^{-1}\right), T$ is absolute temperature, and $E$ is the mean adsorption energy. It is usually applied to differentiate between physical and chemical adsorption. The D-R plot was used to calculate the energy for the dye adsorption [32] system onto composite using equation (8). The energy of dye RY-II was found around $6 \mathrm{~kJ} \mathrm{~mol}^{-1}$, which predicts that the dye uptake on composite was physical adsorption while energy for $\mathrm{MB}$ and $\mathrm{MO}$ dyes were obtained $10 \mathrm{KJ} \mathrm{mol}^{-1}$ and $11 \mathrm{KJ} \mathrm{mol}^{-1}$, this means that dye adsorption takes place by ion-exchange mechanism.
3.5. Kinetics of Adsorption. The adsorption kinetic study is important in predicting the mechanisms (chemical reaction or mass-transport process) that control the rate of the pollutant removal and retention time of adsorbed species at the solid-liquid interface. That information is important in the design of appropriate sorption treatment plants [33].

The adsorption behavior of dyes with time was studied by using different kinetic models like pseudo first order, pseudo second order, and so on; among them, the secondorder equation using the linear form as follows:

$$
\frac{t}{q t}=\frac{1}{\left(K_{2} q e^{2}\right)}+\frac{1}{q e} t
$$

where $K_{2}\left(\mathrm{~g} \mathrm{mg}^{-1} \mathrm{~min}^{-1}\right)$ is the second-order rate constant, Slope $(1 / q e)$ and intercept $\left(1 / K_{2} q e^{2}\right)$ were determined from the linear plot of $t / q t$ versus $t$. The kinetic data were better fitted with pseudo-second-order kinetic model, comparable to pseudo-first-order model. Elovich equation is reported useful in characterizing heterogeneous surfaces or the reaction, which shows the various rate of reactions throughout the space of the adsorption process [14]. The basic equation for Elovich is $q_{t}=\beta^{-1} \ln (\alpha \beta+1)$; it was used modified linearized equation by Chien and Clayton [34] as follows:

$$
q=\frac{1}{\beta}(\ln \alpha \beta)+\frac{1}{\beta} \ln (t),
$$

where $q$ is solute uptake in $\mathrm{mg} \mathrm{g}^{-1}$ at time $t$ (in min) and $\alpha$ and $\beta$ are constants; $\alpha$ is the initial rate constant ( $\mathrm{mg} \mathrm{g}^{-1}$ $\mathrm{min}^{-1}$ ) and $\beta$ is desorption constant $\left(\mathrm{g} \mathrm{mg}^{-1}\right)$. Calculated parameters for second-order kinetics and the Elovich equation are shown in Table 5. All three dyes followed second-order rate constant and Elovich kinetics equation with the regression coefficient of 0.99 and 0.88 , respectively, showing more ion-exchange mechanisms than physical adsorption. The data suggested second-order multiplex kinetics; similar results are reported for phosphorus adsorption onto biochar-LDH composites [14].

3.6. Desorption and Recyclability. To obtain an economically attractive adsorbent, it is important that material can be recycled. Reusability of material and its ability to bind the highest amount of dyes was determined. Desorption of dyes was tested by using aqueous solutions of $\mathrm{NaHCO}_{3}(0.5 \mathrm{M})$, $\mathrm{NaOH}(0.1 \mathrm{M}), \mathrm{HCl}(0.1 \mathrm{M})$, ethanol, methanol, and $0.01 \mathrm{M}$ $\mathrm{NaOH}$ in methanol (Table 6). The highest efficiency achieved 
TABLE 4: Values of fitting parameters obtained from LF and DR isotherms.

\begin{tabular}{|c|c|c|c|}
\hline & MB & MO & RY-2 \\
\hline \multicolumn{4}{|c|}{ Langmuir-Freundlich isotherm parameters } \\
\hline$N_{t}\left(\mu \mathrm{mol} \mathrm{g}^{-1}\right)$ & 242.8219 & 5.27 & 16.2892 \\
\hline$m$ & 0.7162 & 1.23 & 4.6753 \\
\hline$K_{0}^{a}\left(\mathrm{mM}^{-1}\right)$ & 0.0018 & 0.639 & 1.0152 \\
\hline$R^{2}$ & 0.99 & 0.99 & 0.99 \\
\hline \multicolumn{4}{|l|}{ DR isotherm } \\
\hline$X m\left(\mathrm{mgg}^{-1}\right)$ & 6.65 & 4.12 & 0.26 \\
\hline$E\left(\mathrm{KJ} \mathrm{mol}^{-1}\right)$ & 10 & 11 & 6.37 \\
\hline$R^{2}$ & 0.98 & 0.94 & 0.95 \\
\hline
\end{tabular}

TABLE 5: Values for significant factors obtained from the kinetics of sorption.

\begin{tabular}{|c|c|c|}
\hline Dyes & Pseudo-second-order rate constant, $K_{2}\left(\mathrm{~g} \mathrm{mg}^{-1} \mathrm{~min}^{-1}\right)$ & Elovich kinetics, $\alpha\left(\mathrm{mg} \mathrm{g}^{-1} \mathrm{~min}^{-1}\right) ; \beta\left(\mathrm{g} \mathrm{mg}^{-1}\right)$ \\
\hline MB & 0.024559 & $\alpha=441 ; \beta=0.691$ \\
\hline $\mathrm{MO}$ & 0.000126 & $\alpha=99.5 ; \beta=0.253$ \\
\hline RY-II & 0.017385 & $\alpha=4272 ; \beta=0.415$ \\
\hline
\end{tabular}

TABLE 6: Optimization of desorption solvent.

\begin{tabular}{lccc}
\hline Solvents & \multicolumn{3}{c}{ Desorption (\%) } \\
& MB & MO & RY \\
\hline $\mathrm{NaHCO}_{3}(0.5 \mathrm{M})$ & 60 & 70 & 70 \\
$\mathrm{NaOH}(0.1 \mathrm{M})$ & 70 & 85 & 80 \\
$\mathrm{HCl}(0.1 \mathrm{M})$ & 20 & 40 & 35 \\
Ethanol & 80 & 83 & 70 \\
Methanol & 88 & 85 & 80 \\
$\mathrm{NaOH}(0.01 \mathrm{M})$ in methanol & 88 & & 88 \\
\hline
\end{tabular}

TABLE 7: Comparison of adsorption capacity with other LDH and HC composites.

\begin{tabular}{|c|c|c|c|}
\hline Adsorbents & Name of dyes & $\begin{array}{l}\text { Dye sorption capacity } \\
\left(\mathrm{mg} \mathrm{g}^{-1}\right)\end{array}$ & Reference \\
\hline Magnetic graphene oxide nanocomposite & Cationic dye (methylene blue) & 64.23 & [35] \\
\hline MgAl-LDH/biochar composites & Cationic dye (methylene blue) & 406.47 & {$[18]$} \\
\hline $\begin{array}{l}\text { NiFe-LDH nanosheet/carbon fiber } \\
\text { nanocomposite }\end{array}$ & Anionic dye (methyl orange and congo red) & 323.6 and 448.4 & {$[36]$} \\
\hline Diatomite supported layered double hydroxide & Anionic dyes (tartrazine and erythrosine dyes) & 555.6 and 625.2 & {$[37]$} \\
\hline $\begin{array}{l}\text { Magnetite/layered double hydroxide } \\
\text { composite }\end{array}$ & Anionic dye (reactive black) & 150.239 & {$[38]$} \\
\hline $\begin{array}{l}\text { Nanoporous composites of activated carbon- } \\
\text { metal organic frameworks }\end{array}$ & Anionic dyes (direct red 31 and acid blue 92) & 500 and 476 & {$[39]$} \\
\hline LDH/HC composite & $\begin{array}{l}\text { Cationic dye (methylene blue) anionic dyes (methyl } \\
\text { orange and reactive yellow-II) }\end{array}$ & $441,99.5$ and 4272 & $\begin{array}{l}\text { Present } \\
\text { study }\end{array}$ \\
\hline
\end{tabular}

for desorption of three dyes (MB, MO, and RY-II) was $88 \%$ with $0.01 \mathrm{M} \mathrm{NaOH}$ in methanol as compared to other solutions. Reusability of C-4 material was tested using optimized desorption solvent, that is, $0.01 \mathrm{M} \mathrm{NaOH}$ in methanol. The material was found to adsorb all the dyes quantitatively for five regeneration cycles. Adsorption efficiency started to decline slightly after the sixth cycle. This decrease in the removal ability can be related to the loss of composite during the filtration process or incomplete removal of adsorbed dyes.
Table 7 compares prepared LDH:HC composite with other reported $\mathrm{LDH}$ or $\mathrm{HC}$ composites, and the result found that LDH:HC composites have the capacity to remove cationic and anionic dyes simultaneously.

\section{Conclusions}

Different ratios of $\mathrm{LDH}$-biochar composite (C-1 to C-4) were successfully prepared and used for the removal of different dyes. 
Preliminary experiments showed simultaneous removal of $\mathrm{MB}$, $\mathrm{MO}$, and RY dyes using C-4 composite. PXRD diffractogram of LDH shows a sharp and symmetrical peak appearing at a $2 \theta$ value of $11.08,22.5,31.5,34,38.5,46$, and 56 , which correspond to diffraction of the $(003,006,009,012,015,018$, and 110) planes. This revealed that the synthesized LDH was well crystallized and had a layered structure with $R_{3} m$ rhombohedral symmetry [1]. The disappearance of peak intensities with an increasing amount of biochar to $\mathrm{LDH}$ was shown that suggests that the addition of $\mathrm{HC}$ exfoliates the layers of LDHs and incorporates some of the $\mathrm{HC}$ into interlayers, which resulted in the improved adsorptive properties of LDHs. FTIR studies of C-4 composite revealed the presence of $-\mathrm{OH}, \mathrm{NO}_{3}$, and $\mathrm{M}-\mathrm{O}$ bonds with corresponding peaks at $3,200-3,500 \mathrm{~cm}^{-1}, 362 \mathrm{~cm}^{-1}$, and 725 and $570 \mathrm{~cm}^{-1}$, respectively. The MBET surface area of LDH was $19.385 \mathrm{~m}^{2} \mathrm{~g}^{-1}$, and pore volume was $0.044 \mathrm{ccg}^{-1}$ after the addition of $\mathrm{HC}$; the MBET surface area and pore volume of the C- 4 composite were $0.043 \mathrm{~m}^{2} \mathrm{~g}^{-1}$ and $0.00 \mathrm{ccg}^{-1}$, which indicates that pore filling of LDH with HC. SEM analysis confirms that the HC was homogeneously integrated with LDH. Adsorption efficiency of the C-4 composite was optimized by the multivariate technique using the response surface methodology (RSM). Removal efficiency of $100 \%$ was obtained for all three dyes with an adsorption capacity of $243,5.3$, and $16.3 \mu \mathrm{molg}^{-1}$ for $\mathrm{MB}, \mathrm{MO}$, and RY, respectively. Elovich's initial intake rates $(\alpha)$ were 4,272 , 441 , and $99.5 \mathrm{mg} \mathrm{g}^{-1} \mathrm{~min}^{-1}$ for RY, MB, and MO, respectively. Data fitted in various models suggested second-order multiplex kinetics, where the surface heterogeneity response was sorbate dependent. Sorption studies reveal that C-4 composite can remove both cationic as well as anionic dyes simultaneously. The material can further be studied for other charged organic compounds.

\section{Data Availability}

All data are included within the article and as supplementry data file.

\section{Conflicts of Interest}

The authors declare that they have no conflicts of interest.

\section{Acknowledgments}

The authors gratefully acknowledge financial support from the project granted under Pak-US Science and Technology Cooperation Program (No. 6-6/Pak-US/HEC/2015/6).

\section{Supplementary Materials}

EDS spectra, equipment used for synthesis, and statistical tables and graphs are available in the supplementary file. (Supplementary Materials)

\section{References}

[1] J. Li, S. Zhang, Y. Chen et al., "A novel three-dimensional hierarchical $\mathrm{CuAl}$ layered double hydroxide with excellent catalytic activity for degradation of methyl orange," RSC Advances, vol. 7, no. 46, pp. 29051-29057, 2017.
[2] A. Walcarius and L. Mercier, "Mesoporous organosilica adsorbents: nanoengineered materials for removal of organic and inorganic pollutants," Journal of Materials Chemistry, vol. 20, no. 22, pp. 4478-4511, 2010.

[3] D. Mohan, A. Sarswat, Y. S. Ok, and C. U. Pittman, "Organic and inorganic contaminants removal from water with biochar, a renewable, low cost and sustainable adsorbent-a critical review," Bioresource Technology, vol. 160, pp. 191-202, 2014.

[4] K. A. Tan, N. Morad, and J. Q. Ooi, "Phytoremediation of methylene blue and methyl orange using Eichhornia crassipes," International Journal of Environment and Sustainable Development, vol. 7, no. 10, p. 724, 2016.

[5] F. D. Chequer, G. R. De Oliveira, E. A. Ferraz, J. C. Cardoso, M. B. Zanoni, and D. P. de Oliveira, "Textile dyes: dyeing process and environmental impact," Eco-Friendly Textile Dyeing and Finishing, vol. 6, no. 6, pp. 151-176, 2013.

[6] M.-X. Zhu, Y.-P. Li, M. Xie, and H.-Z. Xin, "Sorption of an anionic dye by uncalcined and calcined layered double hydroxides: a case study," Journal of Hazardous Materials, vol. 120, no. 1-3, pp. 163-171, 2005.

[7] G. Farabegoli, L. Pietrelli, E. Rolle, and A. Sabene, "Comparison between biological and chemical-physical treatment for colour removal," Water Science and Technology: Water Supply, vol. 4, no. 5-6, pp. 65-72, 2004.

[8] C. Zaharia and D. Suteu, "Coal fly ash as adsorptive material for treatment of a real textile effluent: operating parameters and treatment efficiency," Environmental Science and Pollution Research, vol. 20, no. 4, pp. 2226-2235, 2013.

[9] L. Bulgariu, L. B. Escudero, O. S. Bello et al., "The utilization of leaf-based adsorbents for dyes removal: a review," Journal of Molecular Liquids, vol. 276, pp. 728-747, 2019.

[10] R.-r. Shan, L.-g. Yan, Y.-m. Yang et al., "Highly efficient removal of three red dyes by adsorption onto $\mathrm{Mg}$-Al-layered double hydroxide," Journal of Industrial and Engineering Chemistry, vol. 21, pp. 561-568, 2015.

[11] G. Crini, G. Torri, E. Lichtfouse, G. Z. Kyzas, L. D. Wilson, and N. Morin-Crini, "Dye removal by biosorption using crosslinked chitosan-based hydrogels," Environmental Chemistry Letters, vol. 17, no. 4, pp. 1645-1666, 2019.

[12] T. Qureshi, N. Memon, S. Q. Memon, H. Yavuz, A. Lachgar, and A. Denizli, "Evaluation of hydrochar efficiency for simultaneous removal of diclofenac and ibuprofen from aqueous system using surface response methodology," Environmental Science and Pollution Research, vol. 26, no. 10, pp. 9796-9804, 2019.

[13] G. Fan, F. Li, D. G. Evans, and X. Duan, "Catalytic applications of layered double hydroxides: recent advances and perspectives," Chemical Society Reviews, vol. 43, no. 20, pp. 7040-7066, 2014.

[14] F. Yang, S. Zhang, Y. Sun, D. C. Tsang, K. Cheng, and Y. S. Ok, "Assembling biochar with various layered double hydroxides for enhancement of phosphorus recovery," Journal of Hazardous Materials, vol. 365, pp. 665-673, 2019.

[15] L. Zhang, L. Li, X. Sun, P. Liu, D. Yang, and X. Zhao, "ZnOlayered double hydroxide@ graphitic carbon nitride composite for consecutive adsorption and photodegradation of dyes under UV and visible lights," Materials, vol. 9, no. 11, p. 927, 2016.

[16] P. Koilraj, Y. Kamura, and K. Sasaki, "Carbon-dot-decorated layered double hydroxide nanocomposites as a multifunctional environmental material for Co-immobilization of $\mathrm{SeO}_{4}{ }^{2-}$ and $\mathrm{Sr}^{2+}$ from aqueous solutions," ACS Sustainable Chemistry \& Engineering, vol. 5, no. 10, pp. 9053-9064, 2017. 
[17] S. Wang, B. Gao, Y. Li, A. R. Zimmerman, and X. Cao, "Sorption of arsenic onto $\mathrm{Ni} / \mathrm{Fe}$ layered double hydroxide (LDH)-biochar composites," RSC Advances, vol. 6, no. 22, pp. 17792-17799, 2016.

[18] L. Meili, P. Lins, C. Zanta et al., "MgAl-LDH/biochar composites for methylene blue removal by adsorption," Applied Clay Science, vol. 168, pp. 11-20, 2019.

[19] S. E. Elaigwu and G. M. Greenway, "Chemical, structural and energy properties of hydrochars from microwave-assisted hydrothermal carbonization of glucose," International Journal of Integrated Care, vol. 7, no. 4, pp. 449-456, 2016.

[20] A. Urbanowska, M. Kabsch-Korbutowicz, M. Wnukowski et al., "Treatment of liquid by-products of hydrothermal carbonization (HTC) of agricultural digestate using membrane separation," Energies, vol. 13, no. 1, p. 262, 2020.

[21] S. A. Khan, S. B. Khan, and A. M. Asiri, "Layered double hydroxide of $\mathrm{Cd}-\mathrm{Al} / \mathrm{C}$ for the mineralization and de-coloration of dyes in solar and visible light exposure," Scientific Reports, vol. 6, Article ID 35107, 2016.

[22] S. Milonjić, A. L. Ruvarac, and M. Šušić, "The heat of immersion of natural magnetite in aqueous solutions," Thermochimica Acta, vol. 11, no. 3, pp. 261-266, 1975.

[23] M. Demirel and B. Kayan, "Application of response surface methodology and central composite design for the optimization of textile dye degradation by wet air oxidation," International Journal of Integrated Care, vol. 3, no. 1, p. 24, 2012.

[24] E. Rosales, M. Sanromán, and M. Pazos, "Application of central composite face-centered design and response surface methodology for the optimization of electro-Fenton decolorization of Azure B dye," Environmental Science and Pollution Research, vol. 19, no. 5, pp. 1738-1746, 2012.

[25] F. Ghorbani and S. Kamari, "Application of response surface methodology for optimization of methyl orange adsorption by Fe-grafting sugar beet bagasse," Adsorption Science and Technology, vol. 35, no. 3-4, pp. 317-338, 2017.

[26] K. Hemmati Kahradeh, E. Saievar-Iranizad, and A. Bayat, "Investigation of hydrothermal process time on the size of carbon micro-and nano-spheres," Journal of Optoelectronical Nanostructures, vol. 2, no. 2, pp. 51-60, 2017.

[27] K. Taha, M. M'hamed, and H. Idriss, "Mechanical fabrication and characterization of zinc oxide ( $\mathrm{ZnO})$ nanoparticles," Journal of Ovonic Research, vol. 11, no. 6, pp. 271-276, 2015.

[28] R. Anbarasan, W. Lee, and S. Im, "Adsorption and intercalation of anionic surfactants onto layered double hydroxides-XRD study," Bulletin of Materials Science, vol. 28, no. 2, pp. 145-149, 2005.

[29] S. Babakhani, Z. A. Talib, M. Z. Hussein, and A. A. A. Ahmed, "Optical and thermal properties of $\mathrm{Zn} / \mathrm{Al}$-layered double hydroxide nanocomposite intercalated with sodium dodecyl sulfate," Journal of Spectroscopy, vol. 2014, Article ID 467064, 10 pages, 2014.

[30] L.-F. Chen, H.-W. Liang, Y. Lu, C.-H. Cui, and S.-H. Yu, "Synthesis of an attapulgite clay@ carbon nanocomposite adsorbent by a hydrothermal carbonization process and their application in the removal of toxic metal ions from water," Langmuir, vol. 27, no. 14, pp. 8998-9004, 2011.

[31] L. K. Koopal, W. H. van Riemsdijk, J. C. M. de Wit, and M. F. Benedetti, "Analytical isotherm equations for multicomponent adsorption to heterogeneous surfaces," Journal of Colloid and Interface Science, vol. 166, no. 1, pp. 51-60, 1994.

[32] A. M. Channa, S. Baytak, S. Q. Memon, and M. Y. Talpur, "Equilibrium, kinetic and thermodynamic studies of removal of phenol from aqueous solution using surface engineered chemistry," Heliyon, vol. 5, no. 6, Article ID e01852, 2019.
[33] N. Ayawei, S. S. Angaye, D. Wankasi, and E. D. Dikio, "Synthesis, characterization and application of $\mathrm{Mg} / \mathrm{Al}$ layered double hydroxide for the degradation of Congo red in aqueous solution," Open Journal of Physical Chemistry, vol. 5, no. 3 , p. 56, 2015.

[34] S. H. Chien and W. R. Clayton, "Application of Elovich equation to the kinetics of phosphate release and sorption in Soils," Soil Science Society of America Journal, vol. 44, no. 2, pp. 265-268, 1980.

[35] J.-H. Deng, X.-R. Zhang, G.-M. Zeng, J.-L. Gong, Q.-Y. Niu, and J. Liang, "Simultaneous removal of Cd (II) and ionic dyes from aqueous solution using magnetic graphene oxide nanocomposite as an adsorbent," Chemical Engineering Journal, vol. 226, pp. 189-200, 2013.

[36] H. Hu, S. Wageh, A. A. Al-Ghamdi et al., "NiFe-LDH nanosheet/carbon fiber nanocomposite with enhanced anionic dye adsorption performance," Applied Surface Science, vol. 511, pp. 1455-1470, 2020.

[37] M. Shamsayei, Y. Yamini, and H. Asiabi, “A novel diatomite supported layered double hydroxide as reusable adsorbent for efficient removal of acidic dyes," International Journal of Environmental Analytical Chemistry, pp. 1-17, 2020.

[38] R. G. L. Gonçalves, P. A. Lopes, J. A. Resende et al., "Performance of magnetite/layered double hydroxide composite for dye removal via adsorption, Fenton and photo-Fenton processes," Applied Clay Science, vol. 179, pp. 105-152, 2019.

[39] M. Hasanzadeh, A. Simchi, and H. S. Far, "Nanoporous composites of activated carbon-metal organic frameworks for organic dye adsorption: synthesis, adsorption mechanism and kinetics studies," Journal of Industrial and Engineering Chemistry, vol. 81, pp. 405-414, 2020. 